\title{
Analysis of the hydration of a bentonite seal in a deep radioactive waste repository
}

\author{
J. Vaunat*, A. Gens ${ }^{1}$ \\ Department of Geotechnical Engineering and Geosciences, Technical University of Catalonia (UPC), \\ c/ Jordi Girona 1-3, Módulo D-2, 08034 Barcelona, Spain
}

Available online 1 August 2005

\begin{abstract}
A deep geological repository for nuclear waste requires the backfilling and sealing of shafts and galleries to block any preferential path for radioactive contaminants. The paper presents the coupled hydromechanical analyses of an in situ test carried out in the HADES underground laboratory in Mol, Belgium. The test examines the effectiveness of an expansive clay seal in a horizontal borehole specifically drilled for this purpose. The analysis covers the phase of seal hydration up to saturation and subsequent pore pressure equilibration. Hydraulic and mechanical constitutive laws suited to expansive clay materials have been chosen for the analyses with all the parameters determined independently of the in situ test. A quite good agreement has been found between test observations and computed results suggesting that the numerical formulation employed is able to reproduce the main features of a real sealing system.
\end{abstract}

(C) 2005 Elsevier B.V. All rights reserved.

Keywords: Backfill material; Bentonite; Case study; Compacted swelling clay; Deep disposal of radioactive waste; Engineered barrier; Finite element modelling; Suction; Unsaturated behaviour; Swelling

\section{Introduction}

The construction of a deep geological repository in a suitable host rock is one of the potential solutions for nuclear waste isolation. Any conceptual design must include the backfilling and sealing of shafts and horizontal drifts to block preferential pathways

\footnotetext{
* Corresponding author. Fax: +34 934017251.

E-mail addresses: jean.vaunat@upc.edu (J. Vaunat), antonio.gens@upc.edu (A. Gens).

${ }^{1}$ Fax: +34 934017251.
}

for radionuclide migration. Often plugs of compacted expansive clays are envisaged for this purpose. Initially the seal will be unsaturated and hydration will proceed by drawing water from the host rock. During this process the clay will expand and develop swelling stresses. It is believed that the final state and effectiveness of the seal may depend on this transient phase so a good understanding of the phenomena involved is required. As seals will be located relatively far from the waste a basically isothermal situation prevails.

To obtain information and experience on this problem, an in situ seal hydration test has been performed

0013-7952/\$ - see front matter (C) 2005 Elsevier B.V. All rights reserved. doi:10.1016/j.enggeo.2005.06.014 
in the HADES underground laboratory (Mol, Belgium) excavated in Boom plastic clay (Volckaert et al., 2000). In this paper a numerical analysis of the test is presented together with comparisons with the observations obtained from the monitoring system of the test. Because the seal is made up of compacted highly swelling clay, the coupling between hydraulic and mechanical phenomena must be explicitly considered. The interaction with intact Boom clay that constitutes the host rock also plays an important role in the evolution of the test and must be included in the analysis. The constitutive laws selected for the computations take into account the specific features of behaviour of expansive clay materials and must encompass both the saturated and the unsaturated regimes. Performance of numerical analyses in connection with well instrumented in situ tests provide a valuable opportunity to assess the capability of coupled codes to represent the real behaviour of sealing systems.

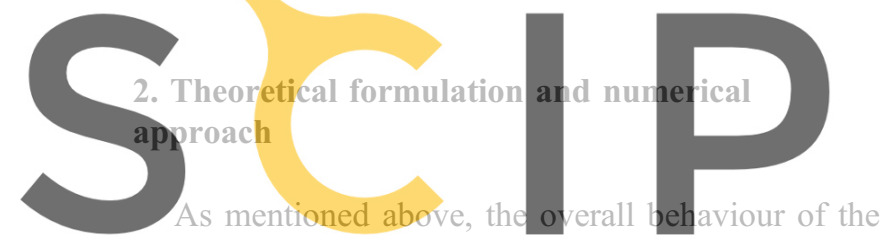

test is controlled mainly by coupled hydro-mechanical

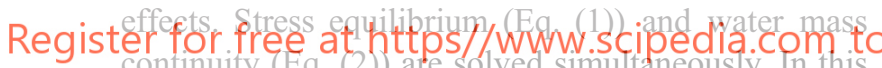
continuity (Eq. (2)) are solved simultaneousty. In this particular case vapour phase flow and air flow are not taken into account. As a consequence, no diffusive fluxes exist. As indicated by Baroghel-Bouny et al. (1999) for the case of non-isothermal processes in cement-based materials, this assumption is not of general application and transport of gases can have significant influence on the global kinetics of the saturation-desaturation process in porous media. Olivella and Gens (2000) further discussed some aspects related to this assumption in clayey materials. They particularly shown that build-up of gas pressure in presence of vapour phase depends on the ratio between material tortuosity and intrinsic permeability. In active clays, intrinsic permeability is affected by microstructural changes that depends themselves on the type of pore fluid. Gas and water permeability tests performed on Serrata clay by Villar (1998) allows for quantifying such effect. Experimental data evidenced a factor of $10^{7}$ between the permeability measured by wetting and non-wetting fluid intrusion. Consequently, it can be reasonably expected that gas pressure build-up will be low during the earlier stages of hydration and will increase only at the very end of the process, when degree of saturation is close to unity. For this reason, assumption of immobile gas has been done in a first step of the analysis, leaving the study of two-phase flow effect for the case in which experimental data invalidate the numerical results. It will be seen in the last part of the paper that hydration of bentonite seal has been well-captured by the present analysis. The simplified set of hydromechanical equations read:

$\operatorname{div}(\sigma)+b=0$

$\frac{\partial\left(n S_{\mathrm{r}}\right)}{\partial t}+\operatorname{div}\left(j_{\mathrm{ml}}^{\mathrm{W}}\right)=0$

where $S_{\mathrm{r}}$ is the degree of saturation, $n$ the porosity and $j_{\mathrm{ml}}^{\mathrm{W}}$ is related to Darcy flux $q_{1}$ by:

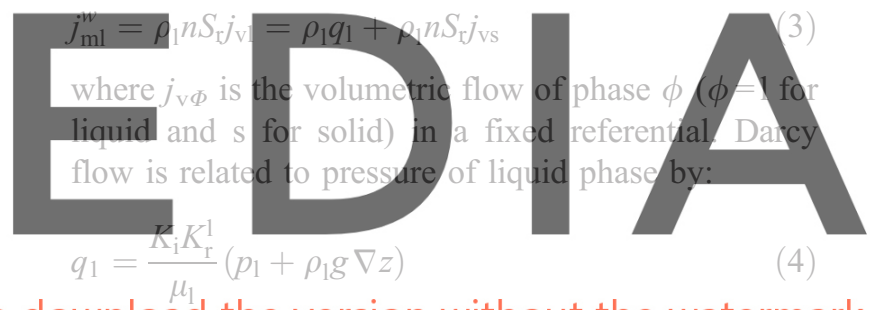

download the version without the watermark where $K_{i}$ is the intrinsic permeability, $K_{\mathrm{r}}^{1}$ is the relative permeability (dependent on degree of saturation), $\mu_{1}$ is the liquid viscosity, $\rho_{1}$ is the liquid density, $g$ the gravity constant and $z$ the elevation. Compressibility and viscosity of water are controlled by the classical parameters used in physics.

The set of balance equations is completed with a number of constitutive laws. Concerning hydraulic phenomena, the retention curve, the variation of the intrinsic permeability $K_{\mathrm{i}}$ with porosity $n$ and the variation of the relative hydraulic conductivity $K_{\mathrm{r}}^{1}$ with degree of saturation $S_{\mathrm{r}}$ are required. For the retention curve, a modified Van Genuchten equation, which avoids infinite suction when degree of saturation goes to residual value, is adopted:

$S_{\mathrm{e}}=\frac{S_{\mathrm{r}}-S_{\mathrm{ru}}}{1-S_{\mathrm{ru}}}=\left(1+\left(\frac{s}{s_{0}}\right)^{\frac{1}{1-\lambda}}\right)^{-\lambda}\left(1-\frac{s}{S_{\mathrm{s}}}\right)^{\lambda_{\mathrm{s}}}$

where $S_{\mathrm{e}}$ is the effective degree of saturation, $S_{\mathrm{ru}}$ the residual degree of saturation, $s$ the suction and the 
remaining variables $s_{0}, s_{\mathrm{s}}, \lambda, \lambda_{\mathrm{s}}$ are parameters. Intrinsic permeability is assumed to depend on porosity in accordance to Kozeny's expression:

$K_{\mathrm{i}}=K_{\mathrm{i} 0} \frac{n^{3}}{(1-n)^{2}} \frac{\left(1-n_{0}\right)^{2}}{n_{0}^{3}}$

where $n$ is porosity and $K_{\mathrm{i} 0}$ the intrinsic permeability for reference porosity $n_{0}$. Depending on the material, relative permeability is defined either by closed form of Van Genuchten expression:

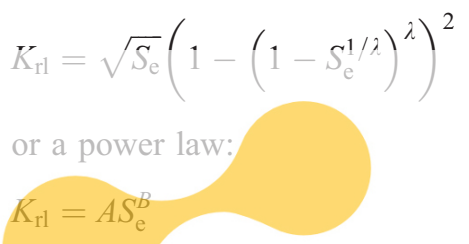

where $A$ and $B$ are parameters.

To describe the unsaturated mechanical behaviour of the materials, a modified version of Barcelona Basic Model (Alonso et al., 1990) fo The main variation concerns the

the type of materials involy

especially important whereas only a minor role. A dependendy of the stress

and suction elastic stiffnesses $K$ and $K_{\mathrm{S}}$ on mean net Registress $p$ and suction have been defined in order to Register for tree at https/pwww scipedia.com to

content on the swelling strain. They read respectively:

$K=\frac{(1+e) p}{\kappa} \quad$ with

$\kappa=\kappa_{0}\left(1-\alpha_{1} s-\alpha_{2} \ln \left(\frac{s+p_{\text {atm }}}{p_{\text {atm }}}\right)\right)$

$K_{\mathrm{s}}=\frac{(1+e)\left(s+p_{\mathrm{atm}}\right)}{\kappa_{\mathrm{s}}}$ with

$\kappa_{\mathrm{s}}=\kappa_{\mathrm{s} 0}\left(1-\gamma \ln \left(\frac{p}{p_{\text {ref }}}\right)\right) \exp (-\delta s)$

and the shear modulus $G$ is derived from the bulk modulus $K$ by considering a constant Poisson's ratio $v$. The plastic part corresponds exactly to the BBM formulation. This model has been chosen in order to have the best fit of experimental data in absence of consideration of more realistic phenomena in relation with bentonite microstructural evolution during wetting/drying cycles. It falls within the class of hypo- elastic models, characterized by the possibility of energy dissipation during application of loading/ unloading/wetting/drying cycles.

The numerical tool CODE_BRIGHT has been used to solve the set of equations. CODE_BRIGHT is a general Finite Element tool, developed to solve nonisothermal multiphase flow and transport in deformable porous media. For more details, the reader is referred to Olivella et al. (1996).

\section{Description of the test and material properties}

\subsection{Test description}

In December 1997, a $270 \mathrm{~mm}$ diameter and $14.7 \mathrm{~m}$ long horizontal borehole drilled in Boom clay formation at a depth of about $330 \mathrm{~m}$ was sealed with precompacted bentonite blocks to study seal effective-

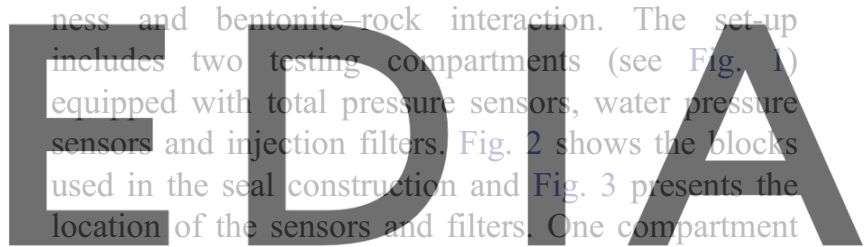

was filled with bricks of Serrata clay at a mean dry downity af $1550 \mathrm{~kg} / \mathrm{m}^{3}$ and the vecond twith bricks of Artificial hydration through injection filters had been planned to begin after convergence of the excavation around the piezometer, corresponding to a radial pressure measured at the contact between the piezometer and the host formation equal to $500 \mathrm{kPa}$. Because the

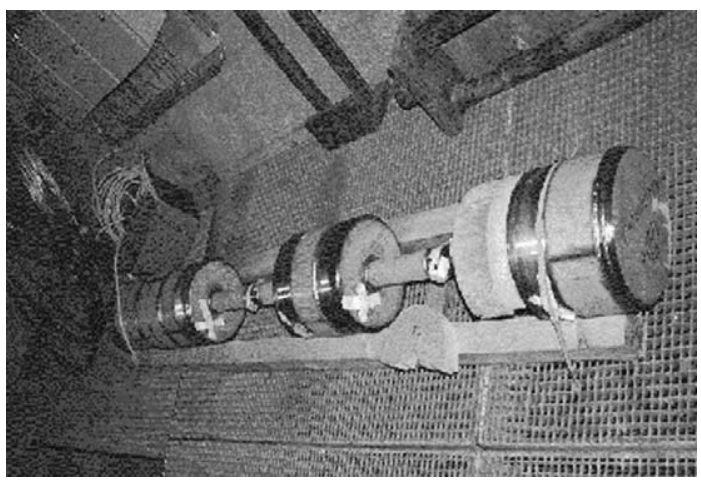

Fig. 1. Set up of the test before installation showing piezometer and filters (Volckaert et al., 1996). 


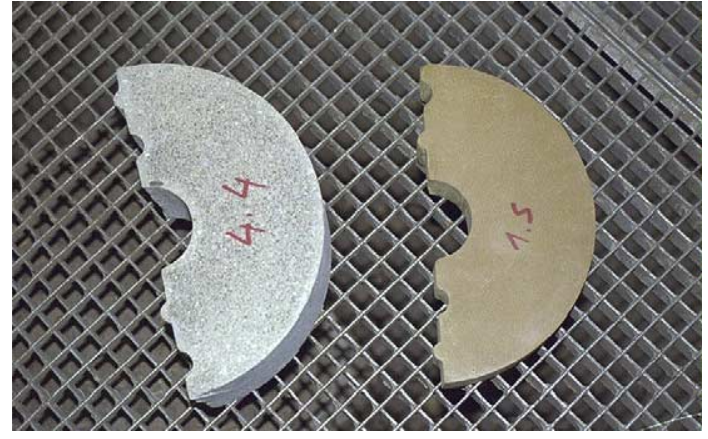

Fig. 2. Blocks of compacted Serrata clay (left) and FoCa clay (right) used in the construction of the seals.
(PTBa, PTBf, PTBg, PTBl) and seven pore water pressure sensors (PW1, PW5 and PW9 to PW13) were installed at the contact with Boom clay formation. Inside each seal, two total pressure sensors measuring the radial stress along the central tube (PTFc and PTFd in FoCa clay plug; PTSi and PTSj in Serrata clay plug), two total pressure sensors measuring the lateral stress at the compartment walls (PTFb and PTFe in FoCa clay plug; PTSh and PTSk in Serrata clay plug) and two pore water pressure sensors (PW2 and PW4 in FoCa clay plug; PW6 and PW8 in Serrata clay plug) were additionally installed.

rate of convergence of the host rock was slower than expected, artificial hydration was started at a nominal pressure value in order not to delay the test schedule. Monitoring of total stresses and pore water pressure was performed throughout the hydration period. The location of the sensors is indicated in Fig. 3. Four
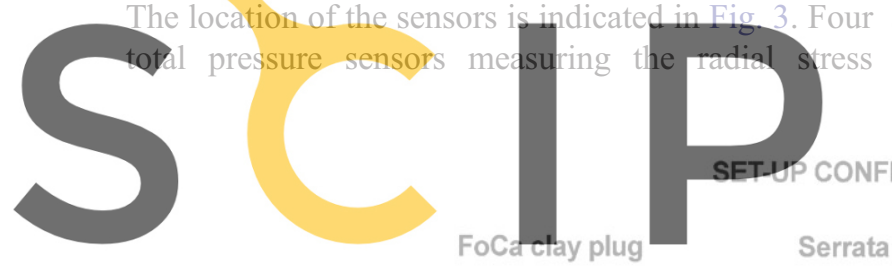

Serrata clay plug

3.2. Material properties

FoCa and Serrata clays are expansive artificial clays that are being considered as potential materials for seals and engineered barriers in the context of nuclear waste disposal. FoCa clay contains $80 \%$ of

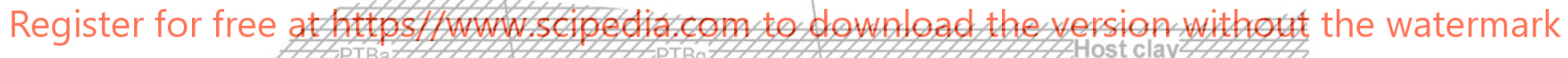
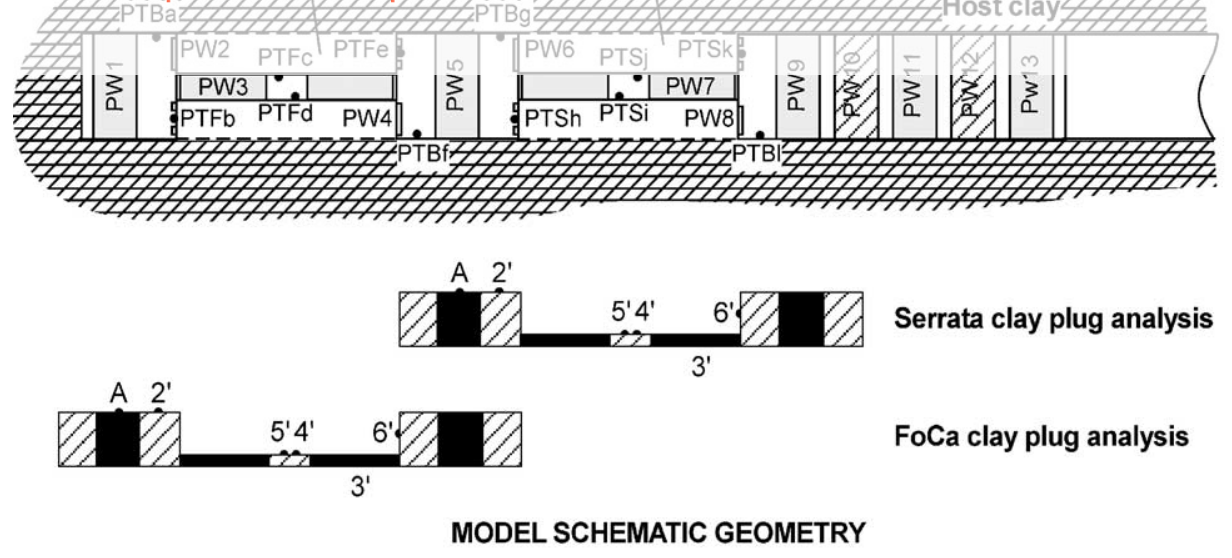

LEGEND PTBx: total pressure sensors at contact with the host clay (indicated by black circles) PTFx: total pressure sensors inside FoCa clay plug (indicated by black circles) PTSx: total pressure sensors inside Serrata clay plug (indicated by black circles) PWx: pore water pressure sensor/ injection filters (indicated by grey and hatched areas) A, $2^{\prime}, 3^{\prime}, 4^{\prime}, 5^{\prime}$ and $6^{\prime}$ : output points of the numerical model

Fig. 3. Scheme of the tests showing monitoring location and computing points. 


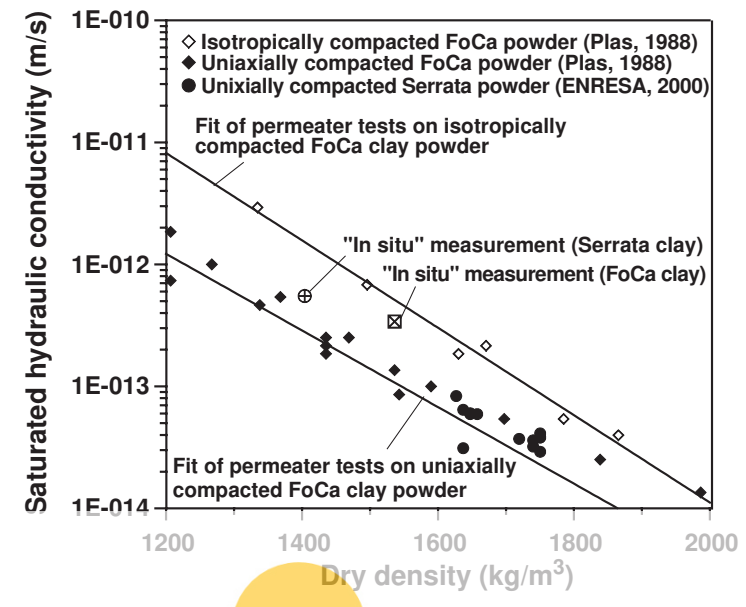

Fig. 4. Experimental results for the relationship between dry density and saturated hydraulic conductivity (data are from Plas (1988) and ENRESA (2000)). liquid limits, $w_{\mathrm{L}}$, is $120 \%$ and its plasticity index, $I_{\mathrm{P}}$,
78. Serrata clay is composed of $93 \%$ of montmorilo-
nite and small percents of non-clay minerals (quartz,
potassium, plagioclase, cristobalite, calcite, volcanic
glass). Its limit liquicis $103 \%$ and its plasticity index,
48 Both materials are composed almost exclusively by clay fraction. Boom clay, the host rock, is a plastic

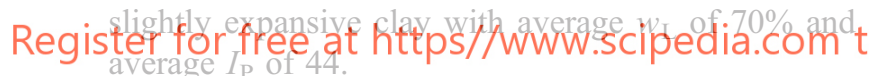

Previously to the in situ test, parameters of FoCa and Serrata clays have been determined from laboratory experiments carried out on samples compacted at distinct dry densities. Hydraulic tests include determination of the retention curves and infiltration tests.

In Fig. 4, the saturated hydraulic conductivity $K_{\mathrm{w}}$ obtained in the laboratory in both oedometer and permeameter tests is represented as a function of the dry density. Values obtained on permeameter tests performed on isotropically compacted samples of FoCa clay powder delimit the upper bound of the laboratory data, whereas the lower bound is given by data obtained by permeameter tests performed on uniaxially compacted samples (with water pressure gradient applied in compaction direction). Serrata clay presents very similar values to that of FoCa clay. These results led to defining initially a conservative set of parameters for Kozeny's expression (Eq. (6)) in order to describe the lower limit of laboratory data. These parameters have been however further modified, taking advantage of additional data provided by a permeability test performed in situ at the end of the seal hydration period and reported in Fig. 4. They indicate indeed that in situ measurements belong to the middle range of laboratory data. Another interesting point coming out from the in situ test is that the average dry density of the hydrated plugs is significantly below the dry density of the bricks, as a result of brick-brick joint closure during seal swelling. Parameters used to represent the variation of intrinsic permeability with porosity are indicated in Table 1 . These parameters are the only ones that have been reassessed on the basis of information coming from the proper in situ test.

Fig. 5 shows the result of laboratory tests performed to determine the retention curve of FoCa clay (Villar, 1998; Volckaert et al., 2000) and Serrata clay (ENRESA, 2000) together with the curves adopted in the analyses. Dark circles define the retention curve of Serrata clay starting from an initial dry

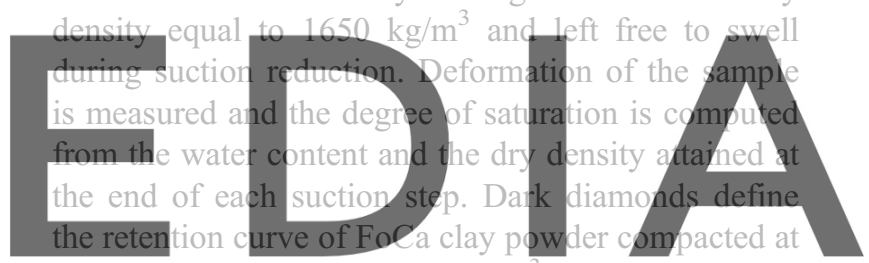

a dry density equal to $1650 \mathrm{~kg} / \mathrm{m}^{3}$ and wetted under

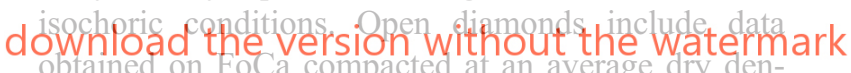
sity equal to $1900 \mathrm{~kg} / \mathrm{m}^{3}$. The points are located above

Table 1

Hydraulic parameters for FoCa clay, Serrata clay and Boom clay

\begin{tabular}{|c|c|c|c|}
\hline Parameter & FoCa clay & Serrata clay & Boom clay \\
\hline \multicolumn{4}{|c|}{ Retention curve } \\
\hline$S_{\mathrm{ru}}$ & 0.0 & 0.01 & 0.0 \\
\hline$s_{0}(\mathrm{MPa})$ & 25.0 & 28.0 & 20.0 \\
\hline$\lambda$ & 0.3 & 0.18 & 0.6 \\
\hline$s_{\mathrm{s}}(\mathrm{MPa})$ & 700.0 & 1100.0 & - \\
\hline$\lambda_{\mathrm{s}}$ & 1.0 & 1.1 & - \\
\hline \multicolumn{4}{|c|}{ Intrinsic permeability } \\
\hline$K_{\mathrm{i} 0}\left(\mathrm{~m}^{2}\right)$ & $3.410^{-20 \mathrm{a}}$ & $5.510^{-21 \mathrm{a}}$ & $4.510^{-19 b}$ \\
\hline$n_{0}$ & 0.426 & 0.495 & - \\
\hline \multicolumn{4}{|c|}{ Relative permeability } \\
\hline$A$ & 1.0 & 1.0 & c \\
\hline$B$ & 3.0 & 3.0 & $\mathrm{c}$ \\
\hline
\end{tabular}




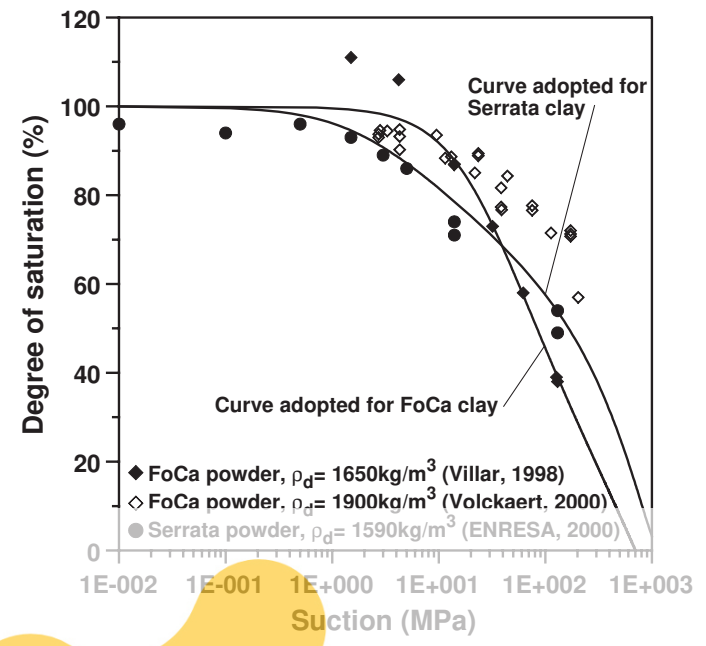

Fig. 5. Retention curve for FoCa and Serrata clays. Experimental data are also shown.

\section{the retention curve obtained for the lower density,}

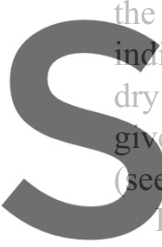

cating that the aip entry p

dry density. A modified Van

Men by Eq. (5) has been used

parameters in Table 1 )

Relative permeability of Serrata clay was assessed

by back analysis of infiltration tests (Villar and Cue-

Register for free at hith hy th wwonent equal to 3 has

puted and experimental water inflow. In absence of

similar tests for FoCa clay at time of the analysis, the same set of parameters has been employed for this material.

Mechanical tests consist of swelling tests, swelling pressure tests, and oedometer loading/unloading tests in both saturated and unsaturated conditions. The tests have been designed according to the stress-suction paths expected in the field and schematically depicted in Fig. 6a. In a sealing plug, hydration takes place mostly under isochoric conditions. The material close to the hydration boundary experiments first a swelling (path $\mathrm{AB}$ ), which compress the dry material far from the hydration condition (path AD). As the hydration proceeds, the compressed material begins to swell due to suction reduction (path DC), which causes a compression of the swollen saturated part of the plug (path $\mathrm{BC})$. A point located in the middle of the plug is expected to experiment a path close to AC.

The mechanical behaviour of both clays, as observed during swelling tests and swelling pressure

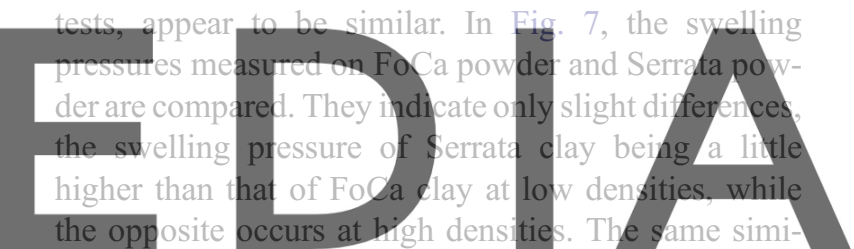

larity can be observed in Fig. 8, which shows the

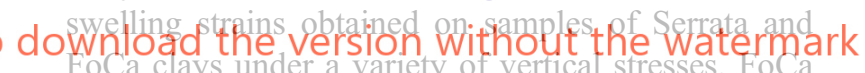
clay samples present higher swelling strains than Serrata clay samples, as a result of their higher initial dry

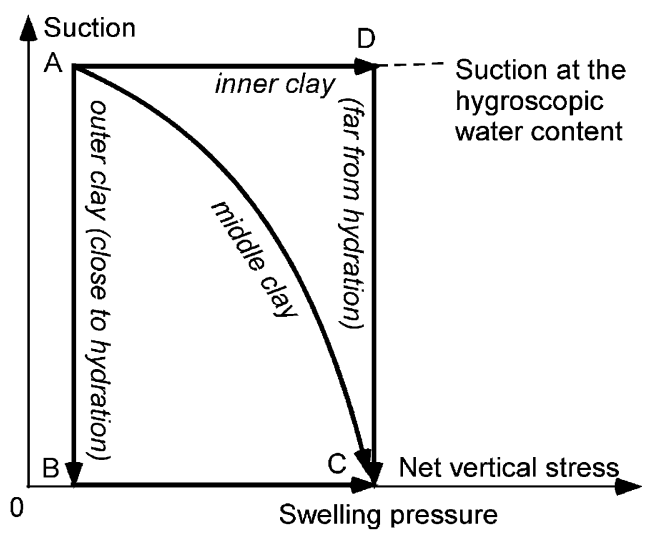

a) Sealing materials

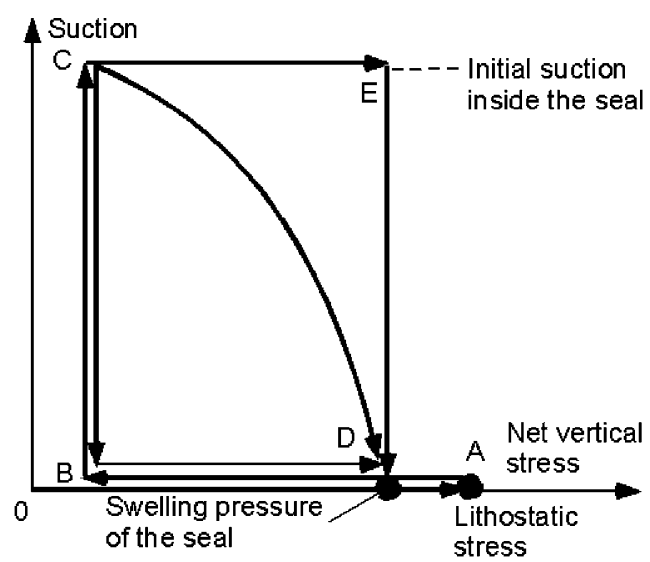

b) Host Clay

Fig. 6. Typical stress-suction paths followed in the laboratory tests. 


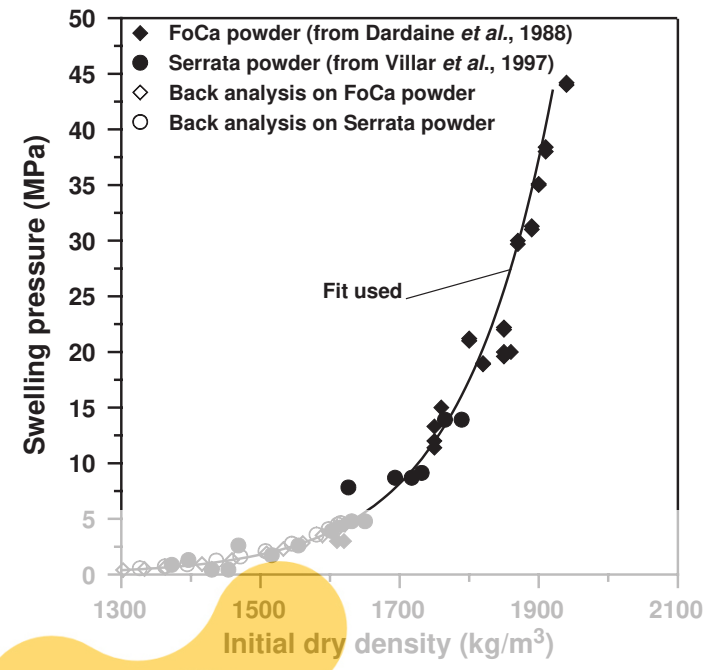

Fig. 7. Variation of swelling pressure with initial dry density of the materials: experimental data and back analysed model results (data are from Dardaine et al. (1988) and Villar et al. (1997)).
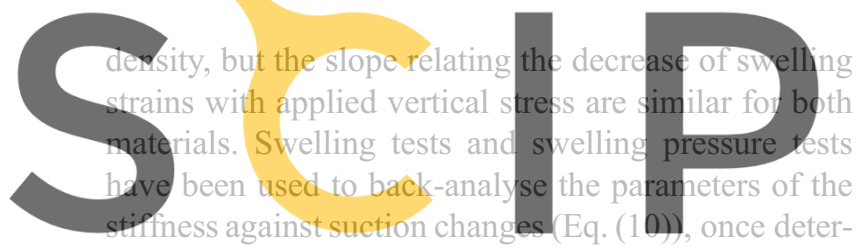

mined the parameters of the stiffness against stress

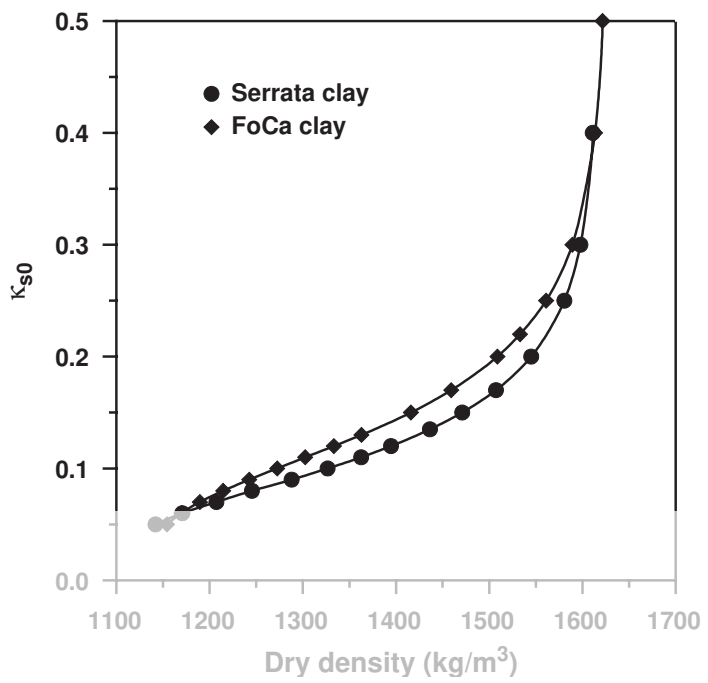

Fig. 9. Variation for the stiffness against suction changes parameter $\kappa_{\mathrm{s} 0}$ as a function of the dry density of the material. Values come from Finite Element back analyses of laboratory swelling pressure

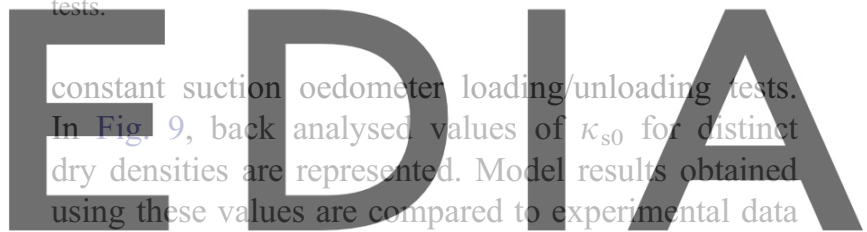

in Fig. 7 (swelling pressure tests on FoCa and Serrata

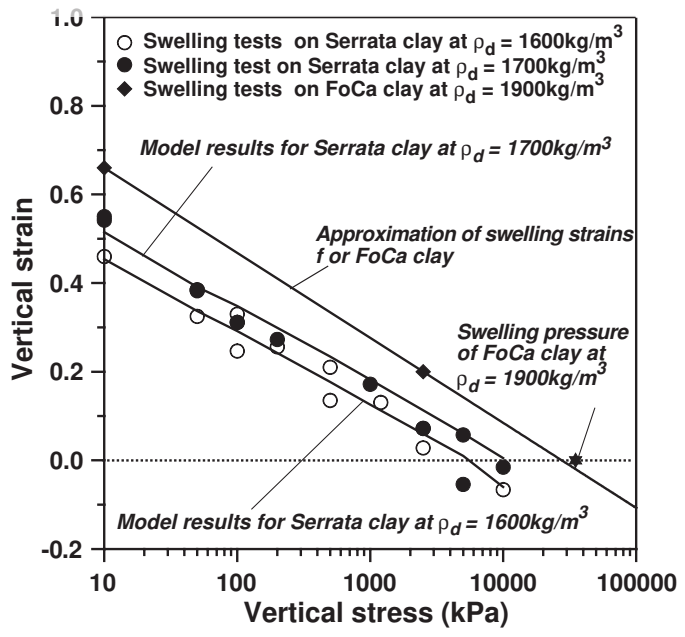

Fig. 8. Experimental results of swelling under pressure tests performed on FoCa clay and Serrata clay. The relationships between vertical strain and vertical stress derived from the mechanical model are shown.

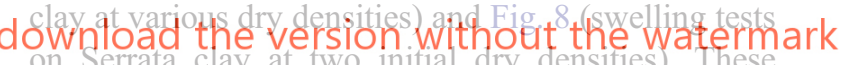

back analyses have been carried out by using the present Finite Element model to solve the Boundary Value problems corresponding to the mentioned laboratory tests. $\kappa_{\mathrm{s} 0}$ values considered for the in situ experiment modelling correspond to the average dry density of the brick/joint system, that are 1360 and $1530 \mathrm{~kg} / \mathrm{m}^{3}$ for, respectively, Serrata and FoCa seals.

The saturated parameters of intact Boom clay were basically determined in the framework of the BACCHUS-2 project (Volckaert et al., 1996; Gens et al., 1995). The assumed preconsolidation pressure at the depth of the experiment is taken from Horseman et al. (1987). Mechanical parameters were assessed by back analysis of the initial phase of the project. Fig. 10 shows, as an example, the comparison between computed pore pressure variations and in situ measurements obtained during BACCHUS-2 excavation process. Some tests concerning the unsaturated response of the host formation have been additionally carried out. The stress-suction paths 


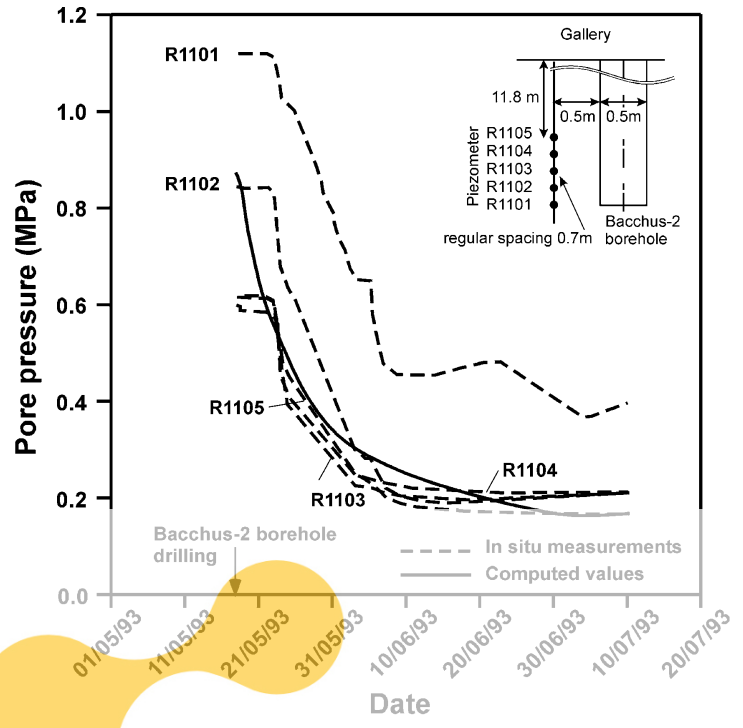

Fig. 10. Comparison between computed and measured water pressure variation after BACCHUS-2 shaft excavation.

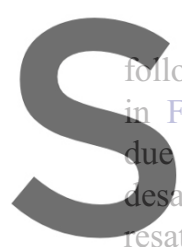

owed during these tests a to excavation process turation after seal installat
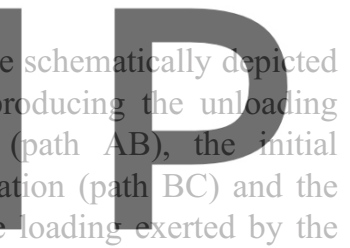

swelling of the seal. In case of a very quick resatura-

Registépufonfreel atehittps/\$waWw/scipediascomioto process and an element inside the host clay will

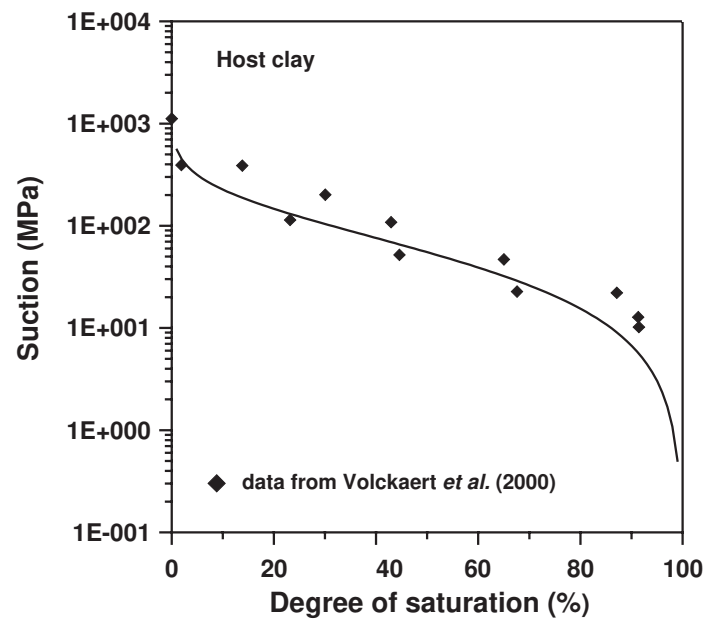

Fig. 11. Experimental results for the determination of the relationship between degree of saturation and suction for intact Boom clay material. The adopted retention curve is shown. follow a path like CBD. If the resaturation is very slow, the swelling seal will cause a loading in dry conditions (path CE) followed by the resaturation of the clay (path ED). When the resaturation takes place at a intermediate rate, suction decrease and stress increase due to seal swelling are combined along a path like CD. Fig. 11 depicts the retention curve adopted for the Boom clay together with the experimental results used for its determination.

The hydraulic parameters for Serrata clay, FoCa clay and intact Boom clay used in the analysis are summarized in Table 1 and the mechanical parameters in Table 2.

Although the analysis reported in this paper corresponds to the so-called final modelling, performed at the end of the in situ test, the parameters used have been determined independently and (with only one significant exception) before the in situ test was performed. This implies that a significant predictive con-

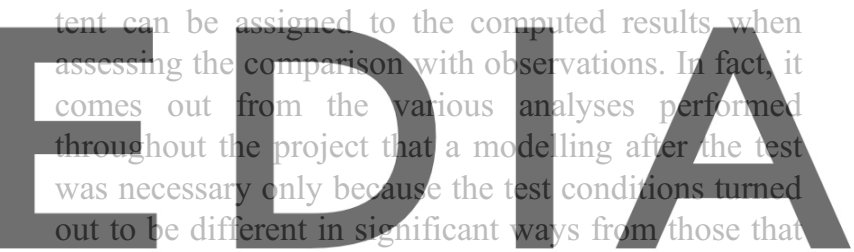

had been originally planned,

download the version without the watermark

Table 2

Mechanical parameters for FoCa clay and Boom clay

\begin{tabular}{llll}
\hline Parameter & FoCa clay & Serrata clay & Boom clay \\
\hline Elastic part & & & \\
$\kappa_{0}$ & 0.1 & 0.05 & $0.0265^{\mathrm{a}}$ \\
$\alpha_{1}$ & 0.0 & 0.0024 & - \\
$\alpha_{2}$ & 0.122 & 0.0 & - \\
$\kappa_{\mathrm{s} 0}$ & 0.22 & 0.11 & $0.00322^{\mathrm{a}}$ \\
$\gamma$ & 0.1638 & 0.1638 & - \\
$\delta\left(\mathrm{MPa}^{-1}\right)$ & 0.03 & 0.0 & - \\
$p_{\text {ref }}(\mathrm{MPa})$ & 0.01 & 0.01 & - \\
$\nu$ & 0.4 & 0.4 & 0.333 \\
& & & \\
$P l a s t i c ~ p a r t$ & & & \\
$M$ & 1.5 & 1.5 & 1.0 \\
$P_{0}^{*}(\mathrm{MPa})$ & $-{ }^{\mathrm{b}}$ & 14.0 & 6.0 \\
$P_{\mathrm{c}}(\mathrm{MPa})$ & $-{ }^{\mathrm{b}}$ & 0.1 & 0.06 \\
$\lambda(0)$ & 0.196 & 0.15 & 0.26 \\
$r$ & $-{ }^{\mathrm{b}}$ & 0.75 & 0.564 \\
$\beta\left(\mathrm{MPa}{ }^{-1}\right)$ & $-{ }^{\mathrm{b}}$ & 0.05 & 0.0544 \\
$k_{\mathrm{s}}$ & $-{ }^{\mathrm{b}}$ & 0.1 & 0.00732 \\
\hline
\end{tabular}

${ }^{\mathrm{a}}$ Assumed constant.

${ }^{\mathrm{b}}$ Not estimated. 


\section{Features and results of the analysis}

\subsection{Geometry, discretization, boundary and initial conditions}

The axisymmetric mesh depicted in Fig. 12 (1140 elements) has been used in the analysis. The boundary conditions are shown on the same figure. An automatic time step procedure is used. To guarantee that a steady state is reached, the computation is continued up to $1 \cdot 10^{9} \mathrm{~s}$ (around 32 years). Output is recorded every ten days.

The bricks of Serrata clay are compacted at a natural water content around $14 \%$ and a dry density equal to $1550 \mathrm{~kg} / \mathrm{m}^{3} \quad\left(n=0.426\right.$ and $\left.S_{\mathrm{r}}=48 \%\right)$. The bricks of Fola clay are compacted at a natural water content around $11 \%$ and a dry density equal to 1660 $\mathrm{kg} / \mathrm{m}^{3}\left(n=0.378\right.$ and $\left.S_{\mathrm{r}}=51 \%\right)$. The suctions prevailing at the beginning of the test inside each seal have been considered to be determined by the bricks

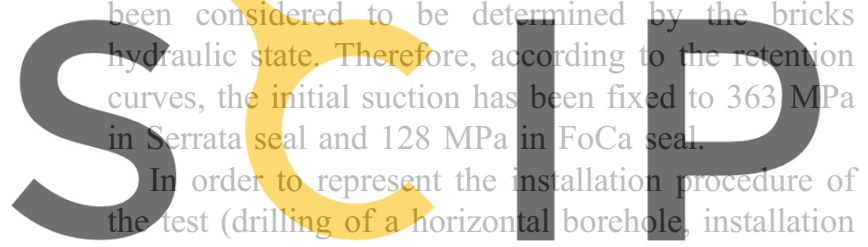

of the piezometer inside the borehole, waiting for convergence of the natural clay around the piezometer) an excavation has been simulated inside the Boom clay formation. Although it was initially envisaged that the artificial hydration would start on reaching a stress of $500 \mathrm{kPa}$ in the seal, it was in fact started earlier. Therefore, inside the buffer, a lower isotropic stress state $\sigma_{x}=\sigma_{y}=\sigma_{z}=50 \mathrm{kPa}$ is initially prescribed. The start of the hydration of the host rock is necessarily uncertain and it was determined from the monitoring results of the test, as explained below.

\subsection{Results}

To examine the results of the analysis, it is necessary to refer to Fig. 3 for the correspondence between sensor locations and computing points.

Fig. 13 shows the evolution of water pressure at the

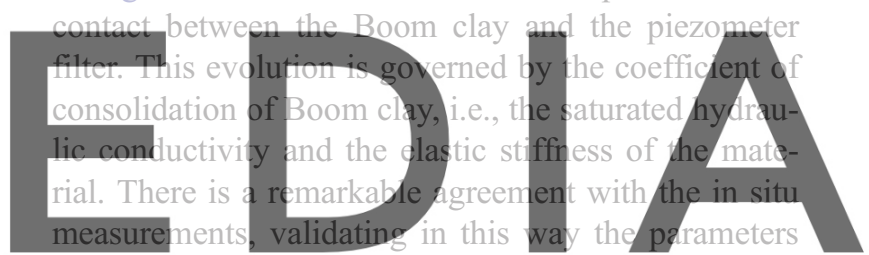

Register for free at httpsw/www.scipedia.com to download the version without the watermark
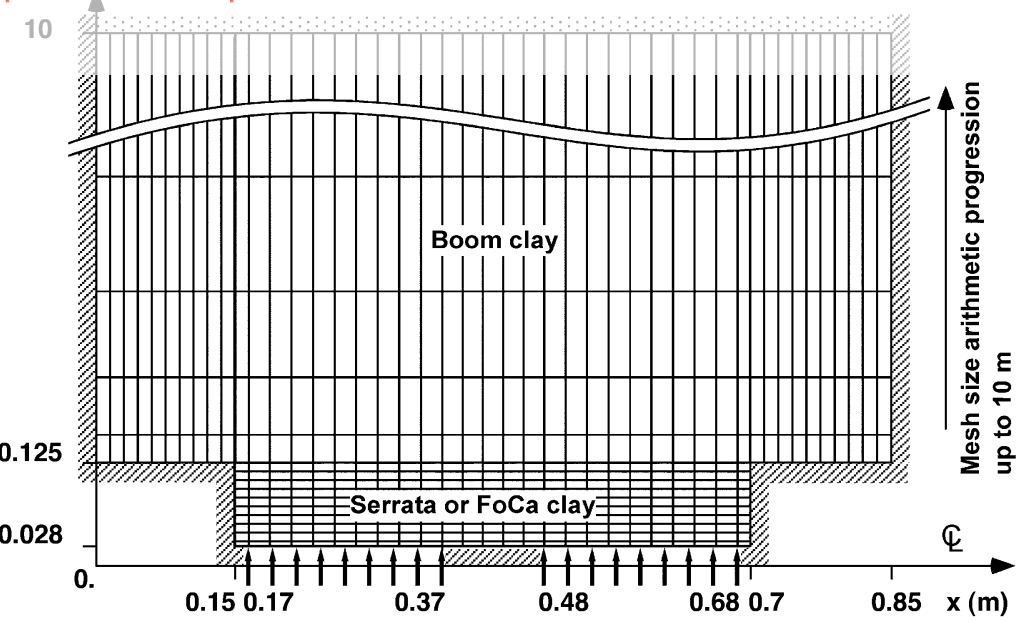

$/ /$ No water flow, no normal displacements, zero shear stress

$\therefore$ Water pressure equal to $2.2 \mathrm{MPa}$, no normal displacements, zero shear stress

$\uparrow$ Water pressure equal to $500 \mathrm{kPa}$ during injection, no water flow after closure of filters, no normal displacements, zero shear stress

Fig. 12. Geometry, space discretization and boundary conditions of the analysis. 


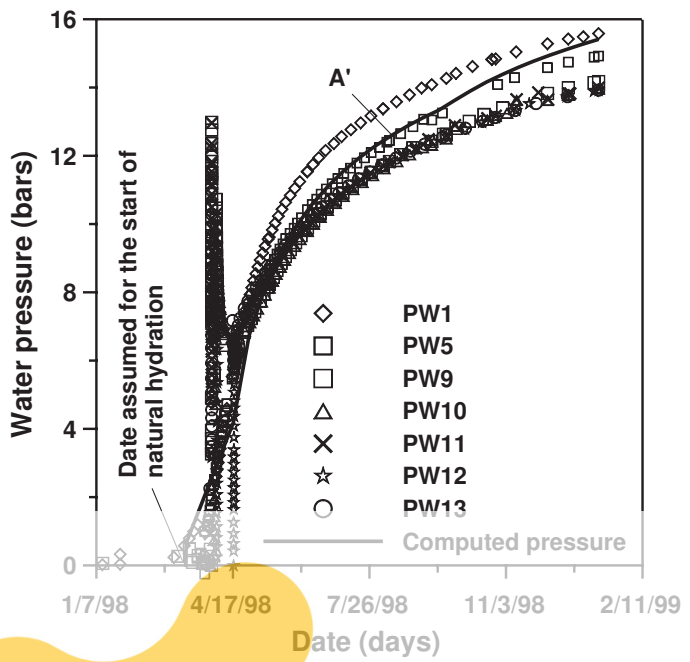

Fig. 13. Comparison between computed and measured water pressures at the contact between the host rock (Boom clay) and the piezometer filter

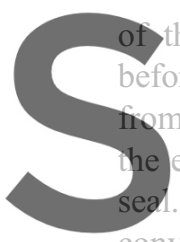

the host formation. The c

before the test considered that

om the host clay and artificial hydration started at and of the convergence of

In reality, natural hydration starts during the convergence of the clay, at an uncertain date. It is in fact nossible to determine this date (March 10th) by

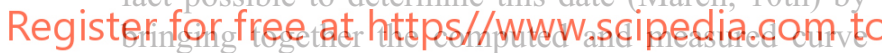

of time evolution of water pressure in the host forma-

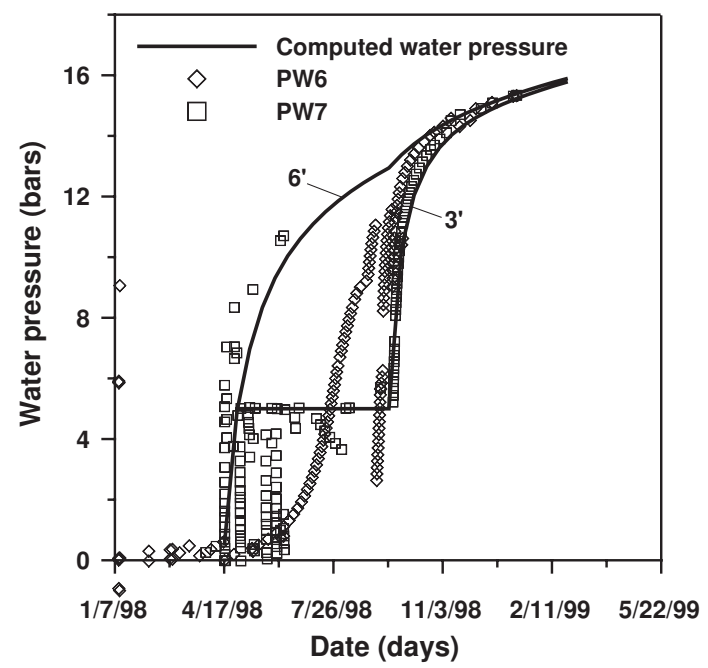

Fig. 14. Comparison between computed and measured pore water pressures in Serrata clay seal.

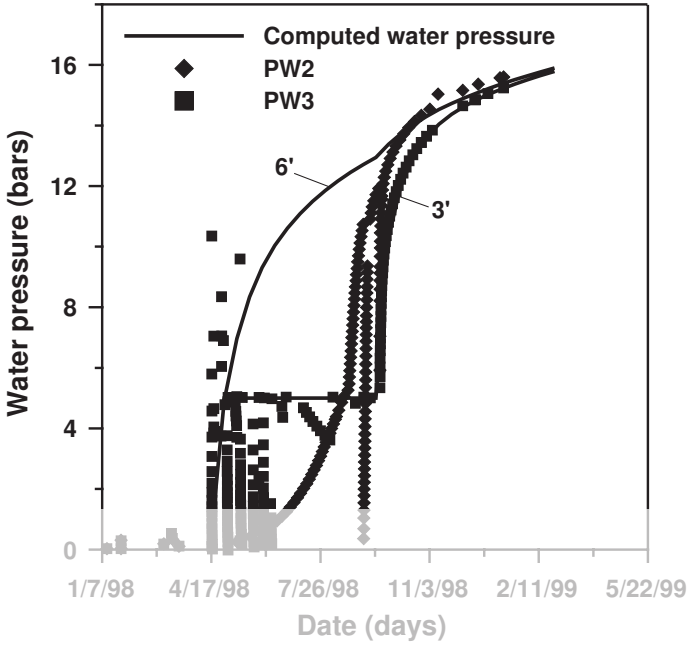

Fig. 15. Comparison between computed and measured pore water pressures in FoCa clay seal.

tion as demonstrated in Fig. 13. This time of begin-

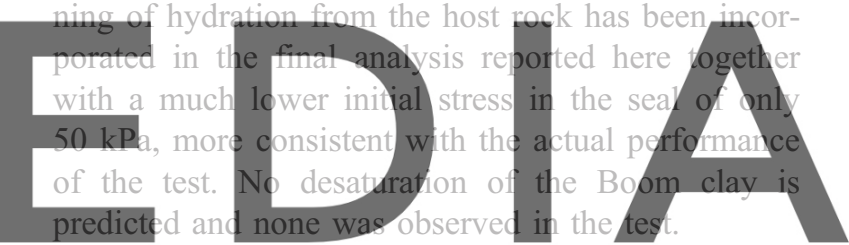

According to the data plotted in Figs. 14 and 15 .

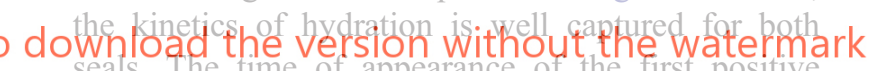
pore pressures is well predicted by the analysis indi-

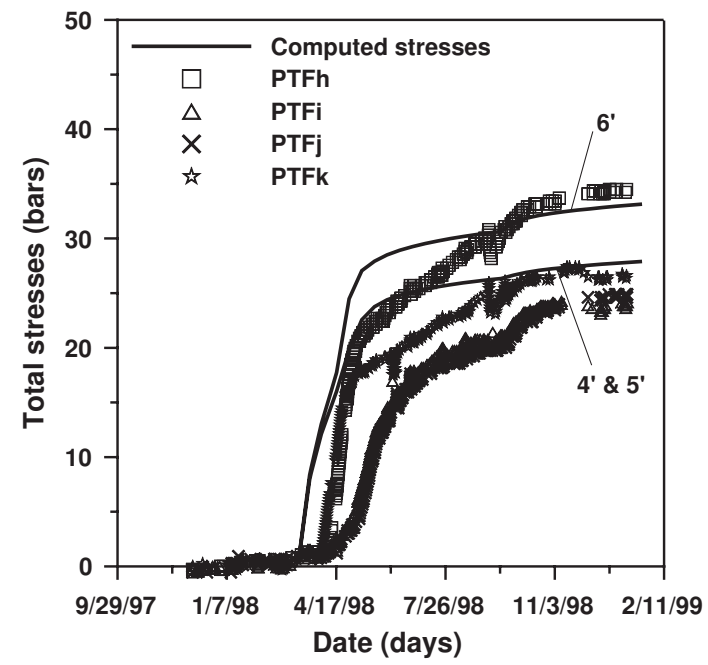

Fig. 16. Comparison between computed and measured total stresses in Serrata clay seal. 


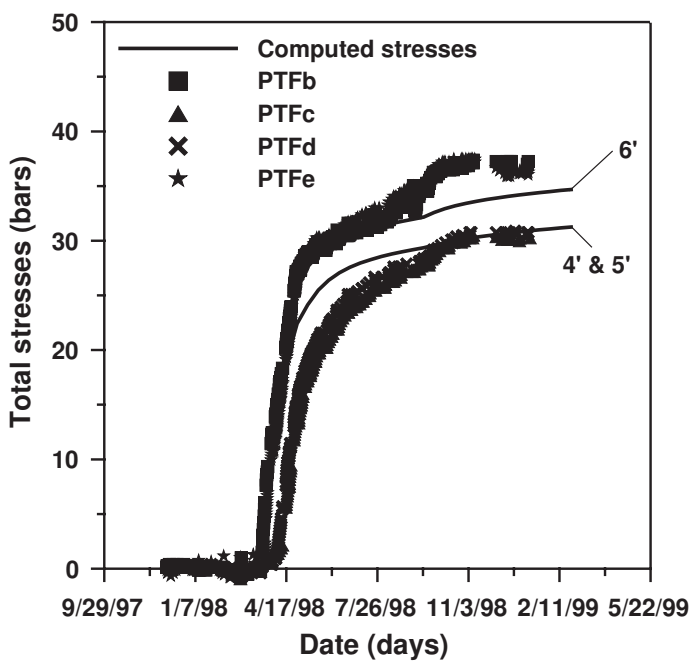

Fig. 17. Comparison between computed and measured total stresses in FoCa clay seal.

cating that the time required for seal saturation is modelled satisfactorily. The computed pore pressure evolution after saturation differs from the observed one; a much faster pore water pressure response was expected. This observation is puzzling as the rate of pore water increase in the long term is well reproduced. A slow piezometer response is in fact suspected due to some air entry in the piezometer cavity during the unsaturated phase of the test. An interesting result of the analysis, confirmed by the test observations, is that the majority of the water required in the hydration of the seal is provided by the host rock, less than $5 \%$ of the total saturation water can be attributed to the artificial hydration.

The computed and observed total stresses are shown in Figs. 16 and 17 where a very good agreement can be noted. The final stresses are very close to the expected swelling pressures, which gives a positive information for the effectiveness of the seal. In fact, the observed axial stresses appear to be somewhat higher than radial stresses as a results of the deformation of the host clay in the radial direction. This difference is also apparent in the stresses obtained in the numerical analyses. Computed and measured dates for which stresses begin to increase in FoCa clay seal agree, whereas a delay in stress build-up starting time is observed in the Serrata seal. Since swelling properties of the materials are very similar, this fact may be due to the different width of the initial gaps that inevitably exist after installation between the total pressure sensors and the adjacent brick. Finally, it is to be noted the late additional increase in total stresses, observed both in the test and the modelling, caused by water pressure equilibration with the hydrostatic distribution prevailing in the host formation. It takes place at almost constant effective stress once the seal swelling transient process is completed.

\section{Concluding remarks}

A numerical analysis incorporating coupled hydromechanical phenomena and involving unsaturated and saturated expansive clays has been performed simulating an in situ sealing test installed in a deep borehole. All parameters have been determined independently from laboratory and in situ testing. A good reproduction of the observed results has been obtained concerning not only the hydromechanical behaviour of the seal but the interaction with the host rock as well. The good agreement between computed results and observations constitutes a significant step towards the validation of this numerical procedure as a computational tool for prediction and design of this type of isolation systems.

\section{Acknowledgements}

This work of performed in the framework of the research project RESEAL financed by the European Commission. Additional support from ENRESA and the Ministerio de Ciencia y Tecnología of Spain (Project BTE2001/2227) is also gratefully acknowledged.

\section{References}

Alonso, E.E., Gens, A., Josa, A., 1990. A constitutive model for partially saturated soils. Géotechnique 40 (3), 405-430.

Baroghel-Bouny, V., Mainguy, M., Lassabatère, T., Coussy, O., 1999. Characterization and identification of equilibrium and transfer moisture properties for ordinary and high-performance cementitious materials. Cement and Concrete Research 29, $1225-1238$.

Dardaine, M., Gatabin, C., Landoas, O., Przybylski, J.P., 1988. Etude expérimentale de la pression de gonflement de quelques 
argiles compactées en fonction des conditions volumiques imposées au cours de leur hydratation. Note Technique SESD/88.21. CEA, Gif sur Yvette, France.

ENRESA, 2000. FEBEX Project: Full Scale Engineered Barriers Experiment for a Deep Geological Repository for High Level Radioactive Waste in Crystalline Host Rock, Final Report. ENRESA, publicación técnica 1/2000, Madrid.

Gens, A., Vaunat, J., Ledesma, A., 1995. Analysis of hydration of an engineered barrier in a radioactive waste repository scheme using an elastoplastic model. In: Alonso, E., Delage, P. (Eds.), Proc. 1st Int. Conf. on Unsaturated Soils. Balkema, Rotterdam, Netherlands, vol. 2, pp. 1065-1073.

Horseman, S.T., Winter, M.G., Entwistle, D.C., 1987. Geotechnical Characterization of Boom Clay in Relation to Disposal of Radioactive Waste. Commission of the European Communities, Luxembourg.

Olivella, S., Gens, A., 2000. Vapour transport in low permeability unsaturated soils with capillary effects. Transport in Porous Media 40, 219-241.

Olivella, S., Gens, A., Carrera, J., Alonso, E.E., 1996. Numerical formulation for a simulator (CODE_BRIGHT) for the coupled analysis of saline media. Engineering Computations 13, 87-112.

Plas, F., 1988. Une méthode de mesure indirecte de la perméabilité des matériaux de type sol: la consolidation uniaxiale. Principe et application é l'argile de référence Fo-Ca. Note technique SESD/ 88.21. CEA, Gif sur Yvette, France.

Villar, M.V., 1998. Ensayos THM para el Proyecto FEBEX. 1st report CIEMAT/DIAE/54111/4/98. CIEMAT. 51 pp, 1998.

Villar, M.V., Cuevas, J., 1996. Caracterización geoquímica de bentonita compactada. Efectos producidos por flujo termo-hidraúlico. Technical Report 54A1512196. CIEMAT, Madrid, Spain.

Villar, M.V., Lloret, A., Linares, J., Pérez, A., 1997. Full-Scale Engineered Barriers Experiment in Crystalline Host Rock. Bentonita (origen, propriedades y fabricación de bloques). Report FEBEX 70-IMA-M-3-3, Madrid, Spain, 140 p.

Volckaert, G., Bernier, F., Alonso, E., Gens, A., Samper, J., Villar, M., Martin Martin, P.L., Cuevas, J., Campos, R., Thomas, H., Imbert, C., Zingarelli, V., 1996. Thermal-hydraulic-mechanical and geochemical behaviour of the clay barrier in radioactive waste repositories (model development and validation). Report EUR 16744 EN, European Commission, Luxembourg.

Volckaert, G., Dereeper, B., Put, M., Ortiz, L., Gens, A., Vaunat, J., Villar, M.V., Martin, P.L., Imbert, C., Lassabatère, T., Mouche, E., Cany, F., 2000. RESEAL, a large scale in situ demonstration test for repository sealing in an argillaceous host rock. Final Report EUR 19612 EN, European Commission, Brussels. 273 pp. 
